\title{
Impacts of Improved Wheat Production Package on Farmers' Productivity and Income in Sudan
}

\author{
Alawia Osman Hassan ${ }^{1 *}$, Abdelaziz A Hashim ${ }^{1}$, Elrashid A Fageer ${ }^{1}$, Ali Chebill ${ }^{2}$, Izzat Tahir ${ }^{1}$ and Solomon Assefa ${ }^{2}$ \\ ${ }^{1}$ Agricultural Research Corporation (ARC), Sudan \\ ${ }^{2}$ International Center for Agricultural Research in the Dry Areas (ICARDA), Sudan \\ Submission: August 27, 2018, Published: September 21, 2018 \\ *Corresponding author: Alawia Osman Hassan, Agricultural Research Corporation (ARC), Sudan, Email: alawiaosh195@yahoo.com
}

\begin{abstract}
This study aims at assessing the adoption of wheat package and impacts of SARD-SC project intervention on wheat production in the Sudan. A field survey was conducted during the season 2015-2016 in the main wheat producing areas, where six innovation platforms (IPs) were established as sites of project interventions in the Northern State, River Nile State, Kassala State, and Gezira State in central Sudan. Primary data was collected through structured questionnaire from a total sample of 544 households ( 253 beneficiaries and 291 non-beneficiaries). This study employed the two step Heckman model to correct for self-selection bias whereas the propensity scores matching and endogenous switching regression methods were employed to assess the impacts. Results of the descriptive analysis indicated that beneficiaries realized yield of wheat higher by $62 \%$ compared to non-beneficiaries across all Sudan. The Northern State accounted for the highest yield, which is higher by $128 \%$ than that of non-beneficiaries, followed by the River Nile State (52\%), Kassala State (39\%) and finally Gezira Scheme (35\%) compared to yield achieved by non-beneficiaries. Likewise, income from wheat was positive and higher for beneficiaries than that of non-beneficiaries. The results showed that farmers' participation in hosting demonstration plots, attending field days, training through farmers field schools within the SARDSC project have significantly enhanced adoption of the recommended wheat package in Sudan. The non-observable factors such as farmers' skills and motivations significantly decreased the area allocated for wheat and the use of Heckman's model corrected bias arising from such factors. The logistic model showed that age of household head and education attainments significantly influenced farmer's participation in SARD-SC wheat technology. According to the results of the propensity score matching method for impact assessment, there were significant differences in yield, wheat income/ha and wheat income/household in the magnitude of 1.39 ton/ha; $804 \$ /$ ha, $2372 \$ / \mathrm{HH}$, respectively between the beneficiary and non-beneficiary groups. The ESR method estimated a yield difference of 1.98ton /ha. The results provide empirical evidence that agricultural technology adoption through SARD-SC intervention has contributed to improved wheat yield and higher farm income of households producing wheat in the Sudan
\end{abstract}

Keywords: Wheat; Adoption; Impact; Heckman; Propensity score matching; Endogenous switching regression; Yield; Income; Sudan

Abbreviations: RMCs: Regional Member Countries; IPs: Innovation Platforms; ATT: American Telephone and Telegraph

\section{Introduction}

Wheat is an important food security crop in the Sudan. SARDSC Project has been introduced to contribute to improved food security and reduced poverty in the African Development Bank's Regional Member Countries (RMCs) with specific objectives to increase wheat productivity and production, optimize the management of scarce natural resources and enhance the capacity of the NARES to conduct needed research for development.

Due to SARD-SC Wheat project activities, mainly generation of agricultural technologies, dissemination and adoption of agricultural technologies, and capacity strengthening of project stakeholders, there is an increase in yield and income of wheat producing farmers. Also, there is a reduction in the total wheat imports. The demand for wheat has increased rapidly in recent years due to changing food habits, population growth and urbanization while production falls short to meet the rising demand leading to increased importation of wheat from the international market. Analysis of baseline survey data (2013) indicated that average wheat yield across all Sudan was about 1.98tons/ha.

The need for impact evaluation is to help policy makers decide whether programs are generating intended effects; to promote accountability in the allocation of resources across public programs; and to fill gaps in understanding what works, what does not, and how measured changes in well-being are attributable to a particular project or policy intervention.

Effective impact evaluation should therefore be able to assess precisely the mechanisms by which beneficiaries are responding to the intervention. These mechanisms can include links through markets or improved social networks as well as tie-ins with other existing policies. The last link is particularly important because 
an impact evaluation that helps policy makers understand the effects of one intervention can guide concurrent and future impact evaluations of related interventions. The benefits of a welldesigned impact evaluation are therefore long term and can have substantial spillover effects [1].

The main objective of this study is to examine the outcome and the impact of SARD-SC project on the sustainability of wheat production with specific objectives to analyze the significant increase in the yield of beneficiaries and households income using ex post evaluation. The methodology for achieving this objective is described in the next section. In Section 3, the empirical results of the study are presented and discussed. The conclusion and recommendations of the study are presented in Section 4 .

\section{Methodology}

\section{Data sources}

Data used in this study were obtained from primary sources. A field survey was conducted in the main wheat producing areas in the Sudan, where six innovation platforms (IPs) were established as sites of project interventions namely Khor Argo in the Northern State, Abu Seleim/Zaidab in the River Nile State, Demiat and Debeira (in New Halfa Agricultural Scheme) in Kassala State, Wad Elbur and Bassatna (in Gezira Scheme) in central Sudan. This survey aims to assess the impact of the project intervention on wheat production during the season 2015-2016. A structured questionnaire was prepared and used to collect primary data through direct interviews with respondents. The data collected included wheat production in 2015-2016, cultural practices and their costs, inputs used (quantity and value), harvesting, extension services, application of the recommended package, other crops income and off-farm income.

The sample households are composed of beneficiaries and non-beneficiaries selected based on their level of participation in the SARD-SC wheat project. A total of 544 (253 beneficiaries and 291 non-beneficiaries) sample households distributed by region were drawn randomly for interview (Table 1). Data collection was conducted by trained enumerators. The collected data was cleaned, coded, and analyzed using STATA Version 14 Software.

Table 1: Distribution of sample by region.

\begin{tabular}{|c|c|c|c|}
\hline Region & Beneficiaries & Non-beneficiaries & Total \\
\hline Northern & 26 & 86 & 112 \\
\hline River Nile & 31 & 67 & 98 \\
\hline Gezira & 128 & 47 & 175 \\
\hline Kassala & 68 & 91 & 159 \\
\hline Total & 253 & 291 & 544 \\
\hline
\end{tabular}

\section{Propensity Score matching method}

Propensity score is defined as the probability of a subject to be assigned to a specific treatment, conditional on the observed covariates [2]. The propensity score matching is a technique of pairing for economic impact studies [3-5]. It has become an alternative method for estimating treatment effects when treatment effect is not random. This approach is widely used to assess the economic impact of technology [6,7]. In this study, it will be used. The main advantage of this method is to reduce selection bias that may present in evaluation [8-11]. If selection bias from unobserved characteristics is likely to be negligible, then PSM may provide a good comparison with randomized estimates. Another advantage of PSM is that does not necessarily require a baseline or panel survey.

PSM applies a series of statistical analyses and test. This technique constructs a statistical comparison group that is based on a model of the probability of participating in the treatment using observed characteristics. Participants are then matched on the basis of this probability to non-participants. The average treatment effect of the program is calculated as the mean difference in outcomes across two groups. A brief description of PSM method is presented below. The average effect of use of SARD-SC wheat technology on outcomes (yield, income, etc..) is specified as:

$$
\tau_{i}=Y_{i}\left(D_{i}=1\right)-Y_{i}\left(D_{i}=0\right)
$$

Where $\tau i$ is the treatment effect (effect due to participation in SARD-SC wheat project), $Y_{i}$ is the outcome on household $i, D_{i}$ is whether household $i$ has got the treatment or not (i.e., whether a household participated in the project or not). However, one should notice that $Y_{i}\left(D_{i}=1\right)$ and $Y_{i}\left(D_{i}=0\right)$ cannot be observed for the same household at the same time. Due to this fact, estimating individual treatment effect $\tau_{\mathrm{i}}$ is impossible and one has to shift to estimating the average treatment effects of the population than the individual one. The most commonly used average treatment effect estimation is the 'average treatment effect on the treated ( $\tau$ ATT) which is specified as:

$$
\tau_{A T T}=E(\tau / D=1)=E[Y(1) / D=1]-E[Y(0) / D=1]
$$

Since the counterfactual mean for those being treated, $E[Y(0) / D=1]$ is not observed, there is a need to choose a proper substitute for it to estimate ATT. Though it might be thought that using the mean outcome of the untreated individuals, $E[Y(0) / D=0]$ as a substitute to the counterfactual mean for those being treated, $E[Y(0) / D=1]$ is possible, it is not a good idea especially in nonexperimental studies. This is because it is likely that components which determine the treatment decision also determine the outcome variable of interest. Therefore, the outcomes of individuals from treatment and comparison group would differ even in the absence of treatment leading to a self-selection bias. However, by rearranging and subtracting $E[Y(0) / D=0]$ from both sides of equation 2 , ATT can be specified as:

$$
E[Y(1) / D=1]-E[Y(0) / D=0]=\tau_{A T T}+E[Y(0) / D=1]-E[Y(0) / D=0]
$$

In equation 3 , both terms in the left-hand side are observables and ATT can be identified with no self-selection bias. That is, if and only if $E[Y(0) / D=1]-E[Y(0) / D=0]=0$. However, this condition can be ensured only in a randomized experiments (i.e., when there is no self-selection bias). Therefore, some identified assumptions must be introduced for non-experimental studies to solve the selection problem. Basically, there are two strong assumptions to solve the selection problem. These are: conditional independence 
assumption and common support condition. For more detailed discussion about PSM see Wodridge [12]; Angrist et al. [13] and Austin [10]. The PSM generated through the logit model should include predictor variables that influence the participation in the program. Table 2 presents the variables used in the logistic regression for our case study.

Table 2: Variables used in the logit model for PSM analysis.

\begin{tabular}{|c|c|c|}
\hline Variable & Type & Definition \\
\hline Wheat Area & Continuos & Area: wheat area \\
\hline Age of HH Head & Continuos & Age: number of years \\
\hline HH Size & Continuos & $\begin{array}{c}\text { Size: Number of HH } \\
\text { member }\end{array}$ \\
\hline $\begin{array}{c}\text { Education Level of HH } \\
\text { Head }\end{array}$ & Dummy & $\begin{array}{c}\text { Edu: } 1 \text { =University, } \\
\text { secondary; } 0 \text { otherwise }\end{array}$ \\
\hline Land Ownership & Dummy & $\begin{array}{c}\text { Land: } 1=0 w n e d ; 0 \\
\text { otherwise }\end{array}$ \\
\hline
\end{tabular}

\section{Empirical results and interpretation}

\section{Descriptive analysis}

Table 3: Comparison of outcomes mean between beneficiary and nonbeneficiary.

\begin{tabular}{|c|c|c|c|c|}
\hline Region & Outcomes & $\begin{array}{l}\text { Benef- } \\
\text { iciary }\end{array}$ & $\begin{array}{c}\text { Non- } \\
\text { Beneficiary }\end{array}$ & $\begin{array}{l}\text { Diffe- } \\
\text { rence }\end{array}$ \\
\hline \multirow{5}{*}{$\begin{array}{l}\text { Nort- } \\
\text { hern }\end{array}$} & Yield (ton/ha) & 4.59 & 2.01 & 2.58 \\
\hline & Wheat income (\$/ha) & 2180.65 & 834.31 & 1346.34 \\
\hline & Wheat income $(\$ / \mathrm{HH})$ & 1363.11 & 1373.59 & 10.48 \\
\hline & Farm income $(\$ / \mathrm{HH})$ & 2232.54 & 2436.13 & 203.58 \\
\hline & HH income $(\$ / H H)$ & 2434.67 & 2631.01 & 196.33 \\
\hline \multirow{5}{*}{$\begin{array}{l}\text { River } \\
\text { Nile }\end{array}$} & Yield (ton/ha) & 3.36 & 2.21 & 1.15 \\
\hline & Wheat income (\$/ha) & 1377.35 & 753.75 & 951.01 \\
\hline & Wheat income $(\$ / \mathrm{HH})$ & 2589.1 & 922.29 & 1666.8 \\
\hline & Farm income $(\$ / \mathrm{HH})$ & 4251.56 & 7744.01 & 3492.44 \\
\hline & HH income $(\$ / H H)$ & 6205.62 & 8329.99 & 2124.36 \\
\hline \multirow{5}{*}{ Gezira } & Yield (ton/ha) & 4.01 & 2.96 & 1.04 \\
\hline & Wheat income (\$/ha) & 1874.07 & 1046.85 & 827.22 \\
\hline & Wheat income $(\$ / \mathrm{HH})$ & 7344.89 & 3969.8 & 3375.09 \\
\hline & Farm income $(\$ / \mathrm{HH})$ & 15628.55 & 12464.62 & 3163.93 \\
\hline & HH income $(\$ / H H)$ & 15675.4 & 12486.62 & 3188.77 \\
\hline \multirow{5}{*}{ Kassala } & Yield (ton/ha) & 3.52 & 2.53 & 0.99 \\
\hline & Wheat income (\$/ha) & 1586.58 & 1005.21 & 581.36 \\
\hline & Wheat income $(\$ / \mathrm{HH})$ & 4490.63 & 4689.21 & 198.57 \\
\hline & Farm income $(\$ / \mathrm{HH})$ & 12031.65 & 12919.46 & 887.81 \\
\hline & HH income $(\$ / H H)$ & 12745.91 & 13889.09 & 1143.18 \\
\hline \multirow{5}{*}{ Total } & Yield (ton/ha) & 3.86 & 2.37 & 1.48 \\
\hline & Wheat income (\$/ ha) & 1767.44 & 903.53 & 863.9 \\
\hline & Wheat income $(\$ / \mathrm{HH})$ & 5380.29 & 2725.85 & 2654.44 \\
\hline & Farm income $(\$ / \mathrm{HH})$ & 11891.11 & 8556.23 & 3334.87 \\
\hline & HH income $(\$ / H H)$ & 12366.99 & 9055.51 & 3311.47 \\
\hline
\end{tabular}

Results of the descriptive analysis indicated that beneficiaries realized yield of wheat higher by $62 \%$ compared to nonbeneficiaries across all Sudan. The Northern State accounted for the highest yield, which is higher by $128 \%$ than that of nonbeneficiaries, followed by the River Nile State (52\%), Kassala State $(39 \%)$ and finally Gezira Scheme (35\%) compared to yield achieved by non-beneficiaries. Likewise, income from wheat was positive and higher for beneficiaries than that of non-beneficiaries [14-17].

Results showed small differences in wheat household incomes between the beneficiary and non-beneficiary group in the northern region while wheat income per hectare was remarkably higher for the beneficiary due to the difference in yield. In the River Nile State, the significant difference in farm income was mainly due to possession of some farmers to orange fruit farms with high value. In Gezira, the difference in farm income was mainly due to the significant difference in wheat household income. No significant difference in Kassala. In general, the total average wheat yield was 3.86 ton/ha for beneficiary compared to 2.37 ton/ha for nonbeneficiary and total average wheat income $\$ / \mathrm{HH} 5380.29$ for beneficiary compared to $\$$ /HH 2725.85 for non- beneficiary [1820] (Table 3).

\section{Propensity Score matching results}

Table 4: Results of the logistic regression.

\begin{tabular}{|c|c|c|}
\hline & Coefficient & T-test \\
\hline Constant & -0.183 & $-3.51^{* *}$ \\
\hline Area & -0.019 & -0.88 \\
\hline Age & 0.25 & $3.40^{* *}$ \\
\hline Size & 0.021 & 0.84 \\
\hline Education & 0.609 & $3.31^{* *}$ \\
\hline Land & 0.214 & -0.87 \\
\hline $\mathrm{N}^{\circ}$ of observation =544 & & \\
\hline LR chi & \\
\hline Prob $>$ chi $^{2}=0.0008^{* *}$ & & \\
\hline
\end{tabular}

*and ${ }^{* *}$ mean significant at $5 \%$ and $1 \%$, respectively.

Table 5: Propensity score matching results.

\begin{tabular}{|c|c|c|}
\hline Outcomes & Outcome Difference (ATT) & T-Test \\
\hline Yield (ton/ha) & 1.39 & $15.68^{* *}$ \\
\hline Wheat income $(\$ / \mathrm{ha})$ & 804.1 & $15.37^{* *}$ \\
\hline Wheat income $(\$ / \mathrm{HH})$ & 2372.53 & $4.935^{* *}$ \\
\hline Farm income $(\$ / \mathrm{HH})$ & 2282.93 & 1.86 \\
\hline HH income $(\$ / \mathrm{HH})$ & 2105.56 & 1.73 \\
\hline
\end{tabular}

*and ${ }^{* *}$ mean significant at $5 \%$ and $1 \%$, respectively.

The results of logit estimation are presented in Table 4. The results show that age and education level of household head significantly influence farmer's participation in SARD-SC technology. The results of the impact of the SARD-SC project technology estimated by PSM are presented in Table 5. The outcome difference (ATT) between the two groups (beneficiary and non-beneficiary) show that the differences are 1.39t/ha; $804 \$ /$ ha, $2372 \$ / H H ; 2283 \$ / H H$ and 2105.6 / HH for Yield, wheat income per ha, wheat income per household, farm income per $\mathrm{HH}$ and Total HH income, respectively. This difference is statistically 
significant at $1 \%$ level for the three outcomes (Yield, wheat income per ha, wheat income per household).

\section{Conclusion}

The main objective of this study is to assess the ex-post impact of SARD-SC project intervention on wheat production in the Sudan. Data used for the analysis were obtained from a total sample of 544 farmers (253 beneficiaries from SARD-SC project and 291 non-beneficiaries) located in main wheat producing areas, where six innovation platforms (IPs) were established as sites of project interventions in the Northern State, River Nile State, Kassala State, and Gezira Scheme in central Sudan. The propensity score matching method was employed to carry out the impact assessment.

The study showed that participation in SARD-SC project for improving wheat production and the dissemination and application of wheat-improved technologies has increased wheat productivity and income from wheat thus contributing to increasing food security and improving livelihoods of producers. The results provide evidence for the effectiveness of linking applied research to development and paving the way towards achieving self-sufficiency in wheat for the country. The results also provide evidence that agricultural technology adoption can contribute to improving productivity and raising income of farm households. Thus, effective extension and technology transfer activities through innovative platforms are important for enhancing adoption and application of modern agricultural technologies.

\section{References}

1. Shahidur R Khandker, Gayatri B Koolwal, Hussain A (2010) Handbook on Impact Evaluation: Quantitative Methods and Practices. World Bank.

2. Rosenbaum PR, Rubin DB (1983) The central role of the propensity score in observational studies for causal effects. Biometrika 70(1): 4155 .

3. Caliendo Marco, Sabine Kopeinig (2008) Some Practical Guidance for the Implementation of Propensity Score Matching. Journal of Economic Surveys 22(1): 31-72.

4. Rosenbaum PR, Rubin DB (1984) Reducing bias in observational studies using subclassification on the Propensity Score. Journal of the American Statistical Association 79(387): 516-524.

5. Smith AJ, Todd PE (2005) Does matching overcome LaLonde's critique

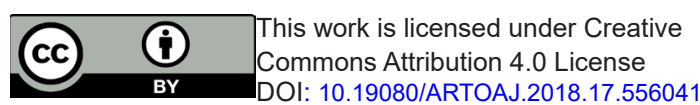

of nonexperimental estimators? Journal of Econometrics 125(1-2): 305-353.

6. Mendola M (2007) Agricultural Technology Adoption and Poverty Reduction: A Propensity-Score Matching Analysis for Rural Bangladesh. Food Policy 32(3): 372-393.

7. Ali A, Erenstein O, Rahut DB (2014) Impact of direct rice-sowing technology on rice producers' earnings: empirical evidence from Pakistan. Development Studies Research 1(1): 244-254.

8. Dehejia RH, Wahba S (2002) Propensity Score-matching Methods for non-experimental Causal Studies. Review of Economics and Statistics 84(1): 151-161.

9. Guo S, Fraser WM (2009) Propensity score analysis: Statistical methods and applications. Sage, Thousand Oaks, California, USA.

10. Austin PC (2011) An Introduction to Propensity Score Methods for Reducing the Effects of Confounding in Observational Studies. Multivariate behavioral research 46(3): 399-424.

11. Steiner PM, Cook TD (2013) Matching and propensity scores. In: Little TD (Edt.), Oxford library of psychology: The Oxford Handbook of Quantitative Methods (Vol. 1). Oxford: Oxford University Press, New York, USA, pp. 237-259.

12. Wooldridge JM (2001) Econometric Analysis of Cross-Section and Panel Data. The MIT Press, Cambridge, Massachusetts, USA, p. 776.

13. Angrist, Joshua D, Jorn-Steffen Pischke (2008) Mostly Harmless Econometrics: An Empiricist's Companion. Princeton University Press, Princeton, New Jersey, USA, p. 392.

14. Dunning Thad (2008) Improving Causal Inference: Strengths and Limitations of Natural Experiments. Political Research Quarterly 61(2): 282-293.

15. Gujarati DN, Dawn Porter (2010) Essentials of Econometrics. ( $4^{\text {th }}$ edn), Mc-Graw-Hill Companies, USA, p. 576.

16. Heckman J, Ichimura H, Smith J, Todd P (1998) Characterizing selection bias using experimental data. Econometrica 66(5): 1017-1098.

17. Heckman James J, Hidehiko Ichimura, Petra Todd (1997) Matching as an Econometric Evaluation Estimator: Evidence from Evaluating a Job Training Programme. Review of Economic Studies 64(4): 605-654.

18. Hirano Keisuke, Guido W Imbens, Geert Ridder (2003) Efficient Estimation of Average Treatment Effects Using the Estimated Propensity Score. Econometrica 7(4): 1161-1189.

19. Jalan J, Ravallion M (2003) Estimating the Benefit Incidence of an Antipoverty Program by Propensity-Score Matching. Journal of Business and Economics Statistics 21(1): 19-30.

20. John L, Wright R, Duku EK, Willms JD (2008) The use of propensity scores as a matching strategy. Research on Social Work Practice 18(1): 20-26.

Your next submission with Juniper Publishers
will reach you the below assets
- Quality Editorial service
- Swift Peer Review
- Reprints availability
- E-prints Service
- Manuscript Podcast for convenient understanding
- Global attainment for your research
- Manuscript accessibility in different formats
( Pdf, E-pub, Full Text, Audio)
- Unceasing customer service
Track the below URL for one-step submission
https://juniperpublishers.com/online-submission.php

